\title{
Praxis Warum nutzten die Maya das Rad nicht, obwohl sie es kannten?
}

$\mathrm{E}$ s gibt zahlreiche archäologische Funde, die zeigen, dass die Maya das Rad kannten. Es handelt sich um Spielzeuge, meistens Tiere, wie Hunde, Katzen oder Jaguare, die auf Achsen mit Rädern gestellt sind. Für den Transport jedoch setzten die Maya das Rad offenbar nicht ein. Baumaterialien für ihre monumentale Architektur, für landwirtschaftliche Produkte oder Handelswaren wurden auf den Schultern, auf Rollen, Tragbahren oder per Boot befördert. Für diese technische Abstinenz werden hauptsächlich zwei Gründe genannt: Das unwegsame Gelände einerseits und der Mangel an Zugtieren andererseits habe den Einsatz von Wagen unattraktiv gemacht. Diese Erklärungen überzeugen mich nicht: Auch wenn sie von Menschen gezogen werden, beschleunigen Wagen die Beförderung und sie erhöhen die mögliche Transportlast, die die einzelne Person bewältigen kann, wie die Existenz von Handkarren in vielen Teilen der Welt belegt. Und was das Gelände betrifft: Es gibt im Siedlungsgebiet der Maya-Stadtstaaten ausgedehnte Flachlandgegenden, die zudem zu Zeiten der Maya von gut ausgebauten Überlandstraßen durchzogen waren. 